\title{
Genomic, genetic and structural analysis of pyoverdine-mediated iron acquisition in the plant growth-promoting bacterium Pseudomonas fluorescens SBW25
}

\author{
Christina D Moon 1,5, Xue-Xian Zhang1,2,6, Sandra Matthijs ${ }^{3}$, \\ Mathias Schäfer ${ }^{4}$, Herbert Budzikiewicz ${ }^{4}$ and Paul B Rainey*1,2,6
}

\begin{abstract}
Address: ${ }^{1}$ Department of Plant Sciences, University of Oxford, South Parks Rd, Oxford OX1 3RB, UK, ${ }^{2}$ School of Biological Sciences, University of Auckland, Private Bag 92019, Auckland, New Zealand, ${ }^{3}$ Laboratory of Microbial Interactions, Department of Molecular and Cellular Interactions, Flanders Interuniversity Institute for Biotechnology, Vrije Universiteit Brussel, Building E, Pleinlaan 2, Brussels, Belgium, ${ }^{4}$ Institut für Organische Chemie der Universität zu Köln, Greinstr. 4, 50939, Köln, Germany, ${ }^{5}$ AgResearch Limited, Grasslands Research Centre, Private Bag 11008, Palmerston North, New Zealand and ' Institute of Molecular Biosciences and New Zealand Institute for Advanced Study, Massey University, Private Bag 102904, Auckland, New Zealand
\end{abstract}

Email: Christina D Moon - christina.moon@agresearch.co.nz; Xue-Xian Zhang - x.x.zhang1@massey.ac.nz; Sandra Matthijs - slmatthi@vub.ac.be; Mathias Schäfer - aco78@uni-koeln.de; Herbert Budzikiewicz - aco88@uni-koeln.de; Paul B Rainey* - p.b.rainey@massey.ac.nz

* Corresponding author

Published: 14 January 2008

BMC Microbiology 2008, 8:7 doi:10.1 |86/|47|-2/80-8-7
Received: 26 June 2007

Accepted: 14 January 2008

This article is available from: http://www.biomedcentral.com/I47I-2/80/8/7

(c) 2008 Moon et al; licensee BioMed Central Ltd.

This is an Open Access article distributed under the terms of the Creative Commons Attribution License (http://creativecommons.org/licenses/by/2.0), which permits unrestricted use, distribution, and reproduction in any medium, provided the original work is properly cited.

\begin{abstract}
Background: Pyoverdines (PVDs) are high affinity siderophores, for which the molecular mechanisms of biosynthesis, uptake and regulation have been extensively studied in Pseudomonas aeruginosa PAOI. However, the extent to which this regulatory model applies to other pseudomonads is unknown. Here, we describe the results of a genomic, genetic and structural analysis of pyoverdine-mediated iron uptake by the plant growth-promoting bacterium $P$. fluorescens SBW25.
\end{abstract}

Results: In silico analysis of the complete, but un-annotated, SBW25 genome sequence identified $3 \mathrm{I}$ genes putatively involved in PVD biosynthesis, transport or regulation, which are distributed across seven different regions of the genome. PVD gene iron-responsiveness was tested using 'lacZ fusions to five PVD loci, representative of structural and regulatory genes. Transcription of all fusions increased in response to iron starvation. In silico analyses suggested that regulation of $f p v R$ (which is predicted to encode a cytoplasmic membrane-spanning anti-sigma factor) may be unique. Transcriptional assays using gene expression constructs showed that $f p v R$ is positively regulated by Fpvl (an extracytoplasmic family (ECF) sigma factor), and not directly by the ferric uptake regulator (Fur) as for PAOI. Deletion of pvdL, encoding a predicted non-ribosomal peptide synthetase (NRPS) involved in PVD chromophore biosynthesis confirmed the necessity of PvdL for PVD production and for normal growth in iron-limited media. Structural analysis of the SBW25 PVD shows a partly cyclic seven residue peptide backbone, identical to that of $P$. fluorescens ATCCI 3525. At least 24 putative siderophore receptor genes are present in the SBW25 genome enabling the bacterium to utilize 19 structurally distinct PVDs from 25 different Pseudomonas isolates.

Conclusion: The genome of $P$. fluorescens SBW25 contains an extensively dispersed set of PVD genes in comparison to other sequenced Pseudomonas strains. The PAOI PVD regulatory model, which involves a branched Fpv signaling pathway, is generally conserved in SBW25, however there is a significant difference in fp $\vee R$ regulation. SBW25 produces PVD with a partly cyclic seven amino acid residue backbone, and is able to utilize a wide variety of exogenous PVDs. 


\section{Background}

Iron is a common co-factor for redox-dependent enzymes and an essential element for almost all living organisms. In nature iron is abundant; however, in aerobic environments and under general physiological conditions, iron typically exists in the insoluble ferric $\left(\mathrm{Fe}^{3+}\right)$ form, thus rendering acquisition by organisms difficult. Under conditions of iron limitation, many bacteria produce and secrete low molecular weight ferric-specific ligands known as siderophores (for review, see [1]). The ferricsiderophores deliver iron to the cell via specific receptor and transport systems (for review, see [2]).

Collectively, Pseudomonas spp. produce a wide variety of siderophores [3], the most complex and common of which are pyoverdines (PVDs) [4]. PVDs contain a peptide moiety, usually between 6-12 amino acids in length, and a dihydroxyquinoline chromophore moiety [4], which gives PVD its characteristic yellow-green fluorescent appearance. PVD-mediated iron uptake processes have been extensively characterized in Pseudomonas aeruginosa PAO1, where key regulatory and structural proteins have been identified, and regulatory mechanisms have been elucidated [5-9].

In P. aeruginosa PAO1, the primary level of PVD regulation involves the ferric uptake regulator (Fur), which, upon interaction with ferrous iron $\left(\mathrm{Fe}^{2+}\right)$, binds to a specific DNA sequence (the Fur-box) in the promoter region of certain iron-regulated genes and blocks transcription. Under iron-deplete conditions (no $\mathrm{Fe}^{2+}$ available to interact with Fur) Fur-dependent repression is relieved $[6,10]$. PAO1 PVD genes that possess Fur boxes, which have been demonstrated to bind Fur in vitro $[5,11]$, are $p v d S$ and $f p v I$, which encode extracytoplasmic family (ECF) sigma factors, and $f p v R$, an inner membrane-spanning anti-sigma factor. The alternative sigma factor, PvdS, when associated with core RNA polymerase, binds iron-starvation (IS) box motifs [12] and directs the expression of a suite of genes involved in the synthesis of PVD $[7,13]$. The activity of $\operatorname{PvdS}$ is regulated by a transmembrane signaling system that comprises of FpvR and FpvA, an outer membrane PVD receptor, and is primarily mediated by PVD [5]. More recently, a second ECF sigma factor (FpvI) was found to direct transcription of $f p v A[5,14]$. Like PvdS, FpvI is also under the direct regulation of FpvR and forms a second divergent branch of the signaling pathway.

Many plant-associated pseudomonads are known to produce PVDs, including the plant pathogen, $P$. syringae and the saprophytes, $P$. putida and $P$. fluorescens. The importance of siderophores for rhizosphere colonization by $P$. putida has been previously reported $[15,16]$. However, little is known about the molecular mechanisms of PVD production and regulation in these organisms.
Here we report a genetic characterization of genes for PVD production in a plant growth-promoting bacterium, $\mathrm{Pseu}$ domonas fluorescens SBW25. SBW25 was originally isolated from field-grown sugar beet [17] and its biocontrol activity against the soil-borne pathogen, Pythium ultimum, is related to its considerable plant colonization ability [18]. The present investigation was prompted by initial findings that three genes implicated in iron-acquisition processes were up-regulated on plant surfaces, as revealed by in vivo expression technology (IVET) analysis $[19,20]$. Two genes had significant homology to putative siderophore receptor genes, and one gene appeared to be homologous to PAO1 $p v d L$, which encodes a non-ribosomal peptide synthetase (NRPS) involved in PVD biosynthesis [21]. These findings suggested a significant role for iron uptake during seedling colonization.

Our work began with the un-annotated whole genome sequence of SBW25 [22]. Based initially on an analysis of this sequence, 31 genes were identified with predicted roles in PVD biosynthesis, transport and regulation, for which the regulation of a subset of these was investigated by genetic analysis using chromosomally-integrated 'lacZ fusions and gene expression constructs. The results indicate a not previously realized mechanism of $f p v R$ regulation. Moreover, we determine the chemical structure of SBW25 PVD and examine the biological role of PVD via a siderophore-deficient mutant. The ability of SBW25 to utilize a panel of structurally distinct exogenous PVDs was also assessed.

\section{Results and Discussion}

Genomic analysis of PVD genes in P. fluorescens SBW25

Interrogation of the complete genome sequence of SBW25 using genes known to be involved in PVD-mediated iron acquisition in $P$. aeruginosa PAO1 [23] revealed 31 homologues with predicted roles in PVD biosynthesis, transport and regulation. The results are summarized in Figure 1 and Additional file 1.

SBW25 homologues were identified for all PAO1 PVD genes except PA2411, which encodes a thioesterase, and $p v d J$ and $p v d D$, which encode NRPSs involved in biosynthesis of the PVD peptide backbone. In PAO1, PA2411 is not essential for PVD production, and is possibly redundant since $p v d G$ also encodes a thioesterase [23]. Although homologues of $p v d J$ and $p v d D$ were not identified in SBW25, three additional NRPS genes were identified: two downstream of pvdP (Pflu2552 and Pflu2553) and one downstream of pvdI (Pflu2544; Figure 1). Differences in the sequences and organization of these NRPS genes likely reflect differences between the structures of the PVDs produced by SBW25 and PAO1 (discussed below). 


\section{P. fluorescens SBW25}
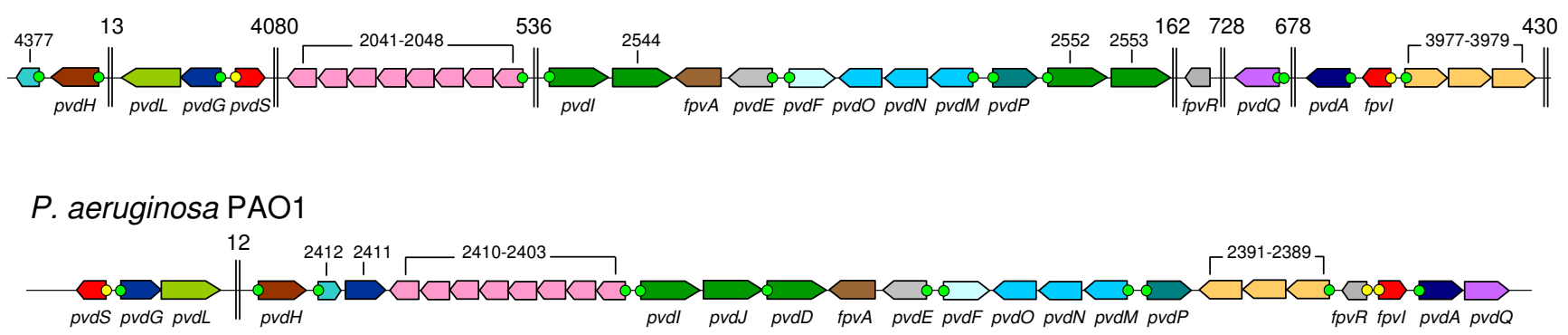

Figure I

Comparison of the arrangement of PVD genes in P. fluorescens SBW25 and Pseudomonas aeruginosa PAOI. PAOI PVD genes are annotated according to [23], and gene names, if given, are shown beneath genes, otherwise PA gene numbers are shown above. PVD gene homologues in SBW25 were identified by BLAST searches, and Pflu gene numbers [22] are shown above genes, if names are not given. Yellow and green dots preceding genes represent sequences that are highly

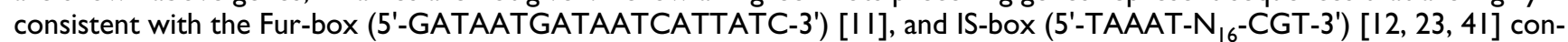
sensus sequences, respectively. Gene sizes are not drawn to linear scale, and double vertical lines represent intervening DNA (sizes in kb shown above). Figure adapted from Ravel \& Cornelis (2003).

The PVD genes of SBW25 are distributed across seven different loci within the genome (Figure 1), which is the most widespread distribution of PVD genes in a genomic comparison among four various sequenced Pseudomonas spp. [23]. This distribution is in stark contrast to that of $P$. syringae where PVD genes form one large cluster [23]. In $P$. aeruginosa PAO1 the PVD genes are confined to two loci separated by just $11.5 \mathrm{~kb}$ (Figure 1), which appears to be typical of $P$. aeruginosa isolates in general, where almost all PVD genes are located within the same region of the genome [24]. PVD gene homologues in P. putida KT2440 and P. fluorescens strains PfO-1 [22] and Pf-5 [25] are distributed across three loci.

Despite the overall differences in the genomic organization of PVD genes between SBW25 and PAO1, genes within each of the seven SBW25 PVD clusters are largely syntenous with those in PAO1. There are, however, two exceptions: $p v d Q$ and $f p v R$, which in SBW25 are found in two non-adjacent regions of the genome and separated from all other PVD genes. The isolated position of $f p v R$ (especially in relation to $f p v I$ - see Figure 1), is particularly unusual: the genes for ECF sigma factors and their cognate anti-sigma factors are typically adjacent, and usually coregulated by Fur $[2,26,27]$. The gene arrangement in SBW25 suggests that $f p v R$ and $f p v I$ might be under separate regulatory control - a notion given credibility by the fact that the promoter sequence of $f p v R$ in SBW25 does not have a recognizable Fur-box motif. Interestingly, in place of the expected Fur-box motif is an IS-box motif, albeit one in which the last three bases of the consensus sequence are in reverse order (TAAAT- $\mathrm{N}_{16}$-TGC, rather than TAAAT- $\mathrm{N}_{16}$-CGT). The possibility that in SBW25 fpvR might be regulated by PvdS led to further investigation (described below).

\section{Expression of putative PVD genes in response to iron starvation}

To ascertain whether the SBW25 PVD gene homologues identified by in silico analyses are responsive to iron, a selection of genes were assessed using chromosomally integrated 'lacZ transcriptional fusions. Genes were chosen that represented key regulatory and structural components in PVD mediated iron-uptake, and included the ECF sigma factor encoding genes $p v d S$ and $f p v I$, the anti-sigma factor encoding gene $f p v R$, and structural genes involved in the biosynthesis and uptake of PVD, $p v d L$ and $f p v A$, respectively (fusion strains TR107.1.1, TR107.4.1, TR107.5.1, TR107.2.1, and TR135.1.1 respectively; Table $1)$. The $\beta$-galactosidase activity of each fusion strain was assessed under high iron $\left(450 \mu \mathrm{M} \mathrm{FeSO}_{4}\right)$, moderate iron (450 $\mathrm{nM} \mathrm{FeSO} 4)$, and low iron (100 $\mu \mathrm{M}$ 2,2'-dipyridyl) conditions. All gene fusions showed decreasing levels of activity as iron concentration was increased (Figure 2), which is consistent with genes that are directly or indirectly under the control of the Fur repressor. The most active gene tested was $f p v A$, the activity of which was almost 3-fold greater than the next most active gene, $p v d S$.

To determine whether SBW25 possesses a branched Fpv signaling pathway analogous to that in PAO1 [5], the effects of the two constitutively expressed ECF sigma factors (PvdS, FpvI) and the anti-sigma factor (FpvR) on downstream structural genes ( $p v d L$ and $f p v A)$ were assessed. Expression constructs (pTR130.1, pTR130.2 and pTR130.3 for $p v d S, f p v I$ and $f p v R$ respectively) were created 
Table I: Bacterial strains and plasmids used in this study.

\begin{tabular}{|c|c|c|}
\hline Strain/plasmid & Relevant genotype and/or other characteristics & Reference \\
\hline \multicolumn{3}{|l|}{ P. fluorescens } \\
\hline SBW25 & Wild-type & {$[17]$} \\
\hline PBR840 & SBW25 $\Delta p v d L$ or $\Delta$ Pflu4387 & This study \\
\hline 15F3 & PBR840 with mini-Tn phoA3 disruption of secondary siderophore biosynthesis genes, $\mathrm{Gm}^{\mathrm{R}}$ & S. Matthijs, unpublished \\
\hline TRI07.I.Ia & SBW25 carrying the pvdS-'IacZ fusion, SmR & This study \\
\hline TRI07.2. $\left.\right|^{\mathrm{a}}$ & SBW25 carrying the pvdL-'lacZ fusion, $\mathrm{Sm}^{\mathrm{R}}$ & This study \\
\hline TRI07.4. $\left.\right|^{\mathrm{a}}$ & SBW25 carrying the $f p v l:: ' / a c Z$ fusion, $\mathrm{Sm}^{\mathrm{R}}$ & This study \\
\hline TRI07.5. $\left.\right|^{\mathrm{a}}$ & SBW25 carrying the fpvR::'lacZ fusion, $\mathrm{Sm}^{\mathrm{R}}$ & This study \\
\hline TRI35.I. Ia & SBW25 carrying the fpvA::'lacZ fusion, $\mathrm{Sm}^{\mathrm{R}}$ & This study \\
\hline TRI37.2.1 & TRI07.2.I with $p \operatorname{Tr} \mid 30.1, \mathrm{Gm}^{R}$ & This study \\
\hline TRI37.3.I & TR 107.2.I with $\mathrm{p} \operatorname{Tr} 130.2, \mathrm{Gm}^{\mathrm{R}}$ & This study \\
\hline TRI37.4.I & TRI07.2.I with $\mathrm{p} \operatorname{Tr} \mid 30.3, \mathrm{Gm}^{\mathrm{R}}$ & This study \\
\hline TRI56.I.I & TR 107.2.I with pBroadgate- $\mathrm{D}, \mathrm{Gm}^{\mathrm{R}}$ & This study \\
\hline TRI38.2.I & TRI35.I.I with $\mathrm{p} \operatorname{Tr} \mid 30.1, \mathrm{Gm}^{\mathrm{R}}$ & This study \\
\hline TRI38.3.I & TRI35.I.I with $\mathrm{p} T r \mid 30.2, \mathrm{Gm}^{\mathrm{R}}$ & This study \\
\hline TRI38.4.I & TRI35.I.I with $\mathrm{p} \operatorname{Tr} \mid 30.3, \mathrm{Gm}^{R}$ & This study \\
\hline TRI56.3.I & TRI35.I.I with pBroadgate-D & This study \\
\hline TRI68.I.I & TRI07.5.I with $\mathrm{p} T r \mid 30.1, \mathrm{Gm}^{\mathrm{R}}$ & This study \\
\hline TRI68.2.I & TRI07.5.I with $\mathrm{p} \operatorname{Tr} 130.2, \mathrm{Gm}^{R}$ & This study \\
\hline TRI68.3.I & TRI07.5.I with $\mathrm{pTr} \mid 30.3, \mathrm{Gm}^{\mathrm{R}}$ & This study \\
\hline TRI68.4.I & TRI07.5.I with pBroadgate-D & This study \\
\hline \multicolumn{3}{|l|}{ Plasmids } \\
\hline pUIC3 & Integration vector with 'lacZ, $T c^{R}$ & {$[20]$} \\
\hline $\mathrm{pHP} 45 \Omega$ & Source of the omega cassette, $\mathrm{Sm}^{\mathrm{R}}$ & {$[51]$} \\
\hline pIVET-Sm & pUIC3 with tet gene replaced by $\mathrm{Sm}^{r} / \mathrm{Sp} r \Omega$ fragment from $\mathrm{pHP} 45 \Omega, \mathrm{Sm}^{\mathrm{R}}$ & This study \\
\hline PUIC3-40 & PUIC3 containing prdL deletion fragment & This study \\
\hline PCR2.1 & $\mathrm{PCR}$ product cloning vector, $\mathrm{Km}^{\mathrm{R}}$ & Invitrogen \\
\hline PRK2013 & helper plasmid, $\mathrm{Km}^{\mathrm{R}}$, $\mathrm{Tra}^{+}$ & {$[52]$} \\
\hline PTRI00.I.I & pIVET-Sm carrying the pvdS-'lacZ fusion & This study \\
\hline PTRI00.2.1 & PIVET-Sm carrying the pvdL-'lacZ fusion & This study \\
\hline PTRI00.4.I & pIVET-Sm carrying the fpvl-'lacZ fusion & This study \\
\hline PTRI00.5.I & PIVET-Sm carrying the fpvR-'lacZ fusion & This study \\
\hline PTRI28.I.I & PIVET-Sm carrying the fpvA-'IacZ fusion & This study \\
\hline pBroadgate & Gateway expression vector with $\mathrm{P}_{\mathrm{lac}}$ promoter, $\mathrm{Gm}^{\mathrm{R}}$ & Thwaites and Mansfield \\
\hline pBroadgate-D & $\mathrm{pBroadgate}$ with $c c d B$ gene replaced with the linker fragment, $\mathrm{Gm}^{\mathrm{R}}$; & [53] \\
\hline PTRI30.I & pBroadgate::pvdS, $\mathrm{Gm}^{\mathrm{R}}$ & This study \\
\hline PTRI30.2 & pBroadgate::fpvl, Gm ${ }^{R}$ & This study \\
\hline PTRI30.3 & pBroadgate::fpvR, GmR & This study \\
\hline
\end{tabular}

a The 'lacZ fusion reporter was integrated into the PVD locus by insertion-duplication thus the gene function was not affected.

in the vector pBroadgate which resulted in the cloned genes coming under the control of the constitutive $\mathrm{P}_{\text {lac }}$ promoter. The expression constructs, and corresponding control vector, pBroadgate- $\mathrm{D}$, were introduced into the pvdL-'lacZ (TR107.2.1) and fpvA-'lacZ (TR135.1.1) fusion strains, and their activities were monitored in $\beta$-galactosidase assays under high and low iron regimes in CAA medium. Expression of $p v d L$ and $f p v A$ was significantly increased as a consequence of constitutive expression of $p v d S$ and $f p v I$, respectively (Figure $3 \mathrm{~A}$ and $3 \mathrm{~B}$ ), consistent with the notion that PvdS and FpvI are alternative ECF sigma factors that direct regulation of each of these genes. In both cases, an increase in expression was observed even in the presence of iron, consistent with Fur-independent regulation of the cloned regulators. Furthermore, expres- sion of $f p v R$ caused a significant decrease in the level of $f p v A$ expression, consistent with FpvR being an anti-sigma factor in the Fpv signaling pathway model [5]. For $p v d L$, repression by FpvR was observed under high iron conditions, though not to a statistically significant level. Thus to verify the presence of the Fpv branched signaling pathway in SBW25, PVD induction of the pathway was demonstrated by providing purified SBW25 PVD to the pvdL-'lacZ and $f p v A-' l a c Z$ fusion strains. Here, the exogenous PVD stimulated the signaling pathway, resulting in significant up-regulation of both $p v d L$ (1.9-fold) and fpvA (3.0-fold; both results significant at $\mathrm{P}=0.05$ using a one-tail t-test). Taken together, these data are consistent with SBW25 possessing a branched Fpv signaling pathway that is activated by PVD. 


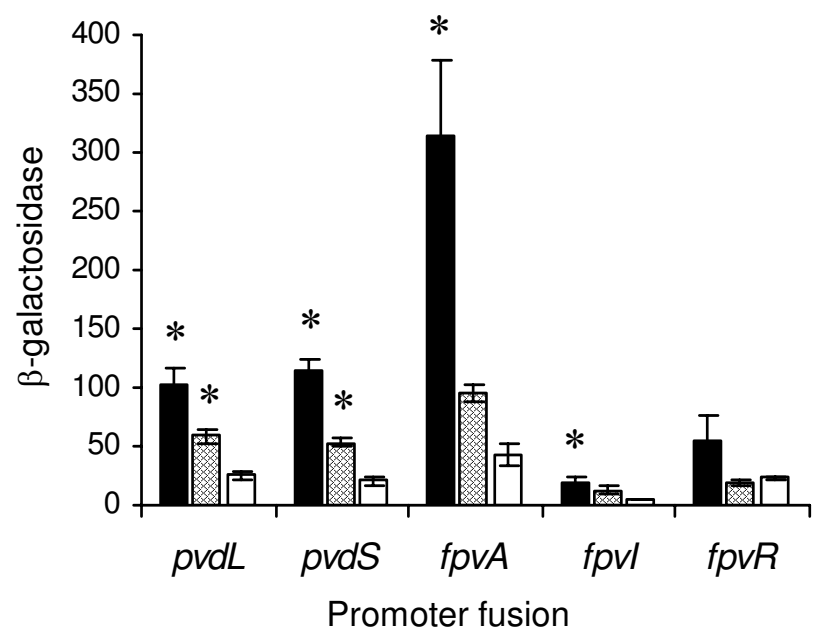

Figure 2

PVD gene activities in response to iron. The activities of $p v d L, p v d S, f p v A$, $f p v l$ and $f p v R$ in response to iron were determined from 'lacZ reporter fusion strains, TRI07.2.I, TRI07.I.I, TRI35.I.I, TRI07.4.I, and TRI07.5.I, respectively. $\beta$-galactosidase activity (fmol $4 \mathrm{MU} / \mathrm{min} /$ cell) was assayed for cells growing in CAA media supplemented with $100 \mu \mathrm{M} 2,2$ '-dipyridyl (black bars), $450 \mathrm{nM} \mathrm{FeSO}_{4}$ (hatched bars), and $450 \mu \mathrm{M} \mathrm{FeSO}_{4}$ (white bars). Data are the means \pm the standard errors of four independent experiments for each strain. Asterisks indicate that the promoter activity in the given iron treatment ( $100 \mu \mathrm{M}$ 2,2'-dipyridyl or $450 \mathrm{nM}$ $\mathrm{FeSO}_{4}$ ) was significantly different to the background activity in $450 \mu \mathrm{M} \mathrm{FeSO}_{4}$ at the $\mathrm{P}=0.05$ level of significance using Dunnett's method.

\section{Unique regulation of fpvR in SBW25}

Next we tested the hypothesis that $f p v R$ is regulated by PvdS rather than Fur, which is the direct regulator of antisigma factors in many other bacterial iron-acquisition systems [27]. The regulatory gene constitutive expression constructs (pTR130.1, pTR130.2 and pTR130.3 for pvdS, $f p v I$ and $f p v R$ respectively) were introduced into the $f p v R$ 'lacZ fusion strain (TR107.5.1). $\beta$-galactosidase activities of the resulting strains were determined under high (450 $\left.\mu \mathrm{M} \mathrm{FeSO}_{4}\right)$ and low (100 $\mu \mathrm{M} 2,2^{\prime}$-dipyridyl) iron regimes. Contrary to expectation, the results presented in Figure $3 \mathrm{C}$ showed that expression of FpvI, and not PvdS, resulted in the up-regulation of $f p v R$, even in the presence of iron. It is unknown whether FpvI directly regulates $f p v R$, or if an intermediate regulatory component is involved. However, a conserved sequence motif, 5'-TAATGAGAA-3', was identified 56 nt upstream of $f p v A$ and 128 nt upstream of $f p v R$, which may potentially serve as an FpvI binding site.

Genomic comparisons suggest that the non-adjacent arrangement of $f p v I$ and $f p v R$ in SBW25 may not be unique. Homologues of $f p v R$ were not reported in $P$. put-
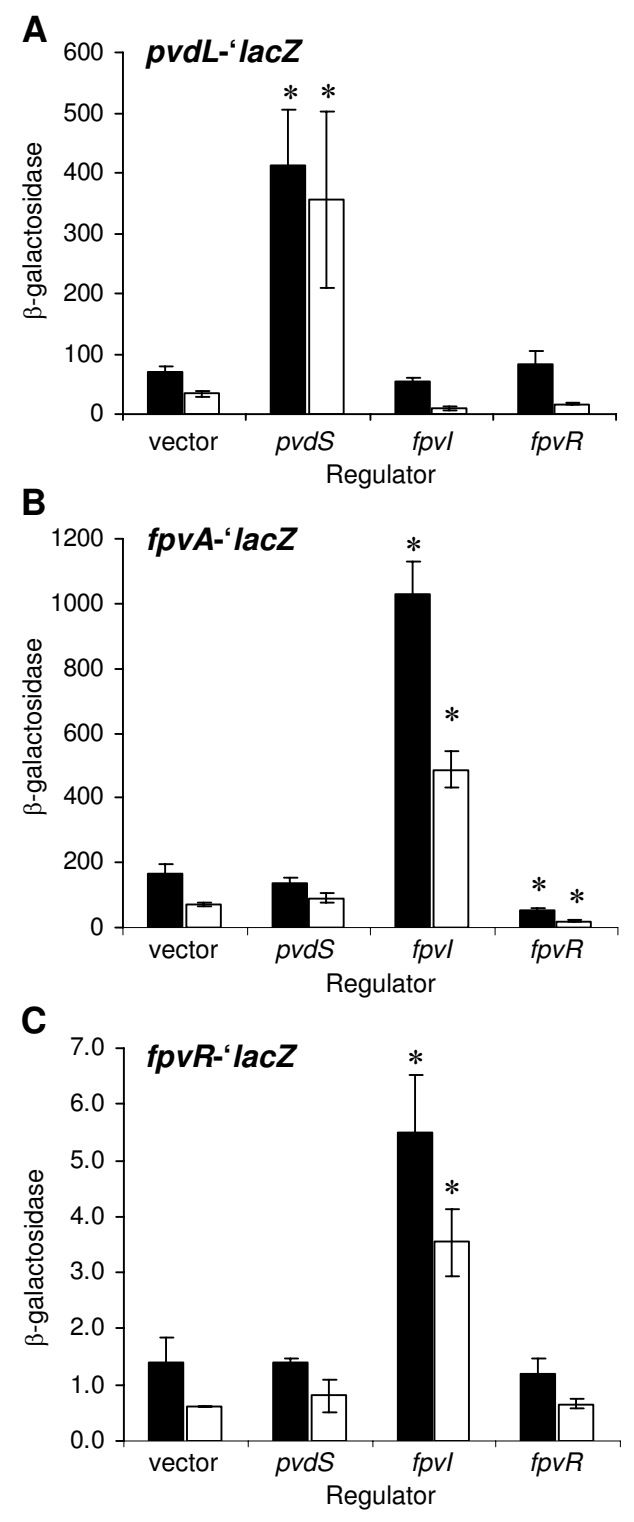

\section{Figure 3}

PVD gene activities in response to constitutivelyexpressed putative regulators. The activities of pvdL-'lac $Z$ (A), fpvA-'lacZ (B), and fpvR-'lacZ (C) (fusion strains: TRI07.2.I, TRI35.I.I, and TRI07.5. I, respectively), in response to constitutively-expressed regulator genes pvdS, $f p v l$, and $f p v R$ (in expression constructs PTRI30.I, PTRI30.2 and PTR I30.3, respectively). $\beta$-galactosidase activity (fmol 4 $\mathrm{MU} / \mathrm{min} /$ cell) was assayed for cells growing in CAA media supplemented with $100 \mu$ M 2,2'-dipyridyl (black bars), or 450 $\mu \mathrm{M} \mathrm{FeSO}_{4}$ (white bars). Data are the means \pm the standard errors of four independent experiments. Asterisks indicate that under the given iron regime, the reporter strain activity with expression construct significantly differs from the background activity of the reporter strain containing the pBroadgate-D (vector) using Dunnett's method at the $P=0.05$ level of significance. 
ida KT2440 and P. fluorescens PfO-1, and fpvR and fpvI were not identified in P. syringae pv. tomato DC3000 [23], however, this is likely to reflect a lack of strong sequence homology to the characterized counterparts in PAO1. Indeed, in SBW25, the amino acid sequence identity between FpvR and its PAO1 homologue was the lowest among all genes examined (48.7\%; Additional file 1). A search for $f p v R$ genes in other sequenced $P$. fluorescens strains revealed putative homologues in PfO- 1 and Pf-5 ( $48.1 \%$ and $48.4 \%$ amino acid sequence identity to PAO1 FpvR, respectively), however neither gene was adjacent to its cognate $f p v I$ homologue, nor possessed a recognizable Fur-box motif in the upstream sequence. A putative IS-box was observed 44 bp upstream of the PfO- 1 homologue, with 7 out of 8 bases matching the IS-box consensus. However, an IS-box was not observed for the Pf-5 homologue, nor was the potential FpvI-binding site sequence identified upstream of SBW2 $2 f p v A$ and $f p v R$. The presence of key genes encoding components of the Fpv branched signaling pathway $(f p v A, f p v R$, pvdS and $f p v I)$ in the PfO-1 and Pf-5 genomes suggests that this pathway may be conserved in these $P$. fluorescens strains - a hypothesis that can be tested in future work.

\section{Deletion analysis of pvdL}

To investigate the biological roles of the PVD genes predicted from in silico analysis, an SBW25 derivative strain containing a deletion of $p v d L$ was constructed (PBR840, $\Delta p v d L$ ). In SBW25, $p v d L$ (Pflu4387) is predicted to encode a 4297 amino acid NRPS involved in PVD chromophore biosynthesis. PBR840 displayed a PVD negative phenotype when grown on LB agar: wild-type SBW25 produced a typical yellow-green siderophore, whereas PBR840 did not (Figure 4A). It was also observed that colonies of PBR840 were notably smaller than those of SBW25 (Figure $4 \mathrm{~A}$ ). It is unknown whether this is solely due to impairment in iron uptake, or whether an iron-independent factor negatively affects PBR840 growth.

The growth kinetics of PBR840 were determined in ironlimited CAA broth and the same medium supplemented with $450 \mu \mathrm{M} \mathrm{FeCl}_{3}$ in microtitre plate cultures. Results are shown in Figure 4B. A repeated measures MANOVA (see figure caption for details) showed that the optical density of PBR840 cells was significantly reduced compared to wild-type in iron deplete medium from $14 \mathrm{~h}\left[\mathrm{~F}_{1,8}=28.02\right.$, $P<0.0001]$. No significant reduction was detected during exponential growth, for example, at 4,6 and $8 \mathrm{~h}, P$ values were $0.849,0.333$ and 0.398 , respectively. No significant difference in growth was observed between wild-type and PBR840 in iron replete medium $\left[\mathrm{F}_{1,8}=0.03, P=0.862\right]$.

Growth analysis of PBR840 took place initially in $200 \mu \mathrm{l}$ microtitre plate cultures, which although incubated with periodic shaking, could have become oxygen limited thus
A

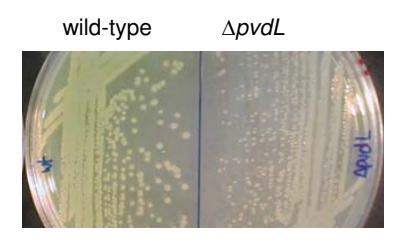

B
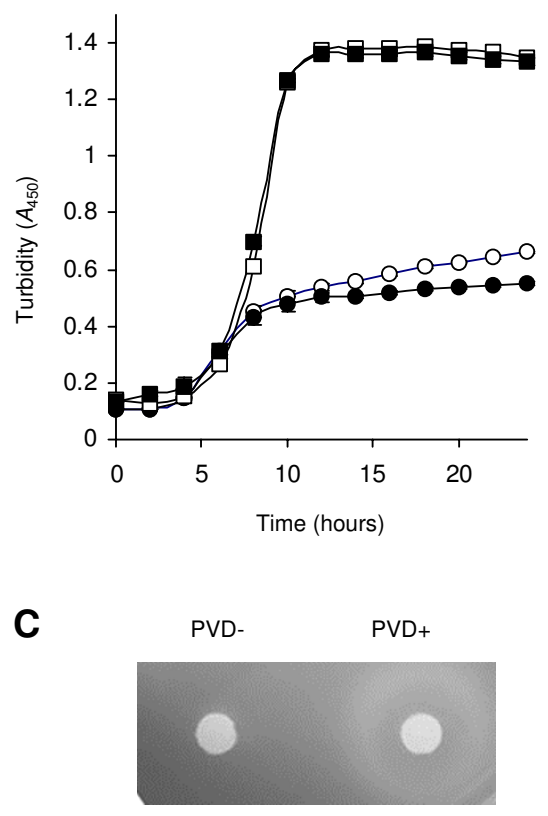

\section{Figure 4}

Growth phenotype of mutant PBR840 ( $\triangle$ pvdL) in iron-limited media. A: Growth of SBW25 and PBR840 on LB agar for two days, after which the mutant produced no visible PVD and colonies were smaller than wild-type. B: Growth in CAA broth (SBW25, clear circle; PBR840, filled circle) and in CAA broth supplemented with $450 \mu \mathrm{M} \mathrm{FeCl}_{3}$ (SBW25, clear square; PBR840, filled square). Results are means and standard errors from at least five independent cultures (error bars are contained within the symbols). Data were collected at 5 minute intervals, but 2 hourly time points are shown for clarity. Data from each medium were analyzed separately using a multivariate model (MANOVA) with repeated measures ( $2 \mathrm{~h}$ intervals): no significant difference was detected between genotypes grown in CAA supplemented with $\mathrm{FeCl}_{3}\left[\mathrm{~F}_{1,8}=0.03, P=0.862\right]$, however, a significant genotype effect was evident in iron deficient medium $\left[\mathrm{F}_{1,8}=37.22, P<0.00 \mathrm{I}\right]$. An analysis at each time point revealed a highly significant difference between genotypes from (and including) the $14 \mathrm{~h}$ time point $\left[\mathrm{F}_{1,8}=28.02, P<\right.$ 0.000 I]. C: PBR840 cells were plated on CAA media with EDDHA and overlaid with filter paper disks impregnated with sterile water (left) and 50 nmol purified SBW25 PVD (right). PBR840 was not able to grow on the strongly ironchelated media, growth was restored when supplemented with PVD. 
masking the effect of the pvdL mutation during exponential growth. To test this hypothesis, growth of PBR840 and SBW25 was further investigated using strongly aerated cultures grown in CAA broth, where iron is more likely to be present in the ferric form. The growth dynamics (data not shown) were comparable to those observed in the static cultures, with no statistical difference in cell density being detected during exponential growth, however differences in final yield were evident at 24 hours (the mean A450 reading and standard error for PBR840 was 0.9239 $\pm 0.014(\mathrm{n}=4)$, and for SBW25 was $1.3510 \pm 0.016(\mathrm{n}=$ 4)). Furthermore, PBR840 was incapable of growing in CAA medium supplemented with the strong iron-chelator EDDHA (ethylenediaminedihydroxyphenylacetic acid, $0.5 \mathrm{mg} / \mathrm{ml}$ ), whereas growth was restored upon provision of purified SBW25 PVD (Figure 4C). Taken together, the data confirmed the predicted role of pvdL (Pflu4387) in PVD production.

\section{Structural analysis of SBW25 PVD}

The chemical structure of SBW25 PVD was determined by mass spectral analysis using standard methods as previously described [28]. Comparison of the mass spectra to published data [29-32] revealed that SBW25 PVD comprises the characteristic PVD quinoline chromophore [33] linked to a partly cyclic seven residue peptide backbone, identical to that of $P$. fluorescens ATCC 13525 [34]: SerLys-Gly-fOHOrn-c(Lys-fOHOrn-Ser) (fOHOrn $=N^{5}$ formyl- $N^{5}$-hydroxyornithine and underlined residues are in the D configuration) (Figure 5). The side chain that is connected amidically to the $\mathrm{NH}_{2}$-group of the chromophore varied as succinic acid or ketoglutaric acid. The peptide backbone sequence differs in length and composition to that of PAO1 PVD (Ser-Arg-Ser-fOHOrn-c(LysfOHOrn-Thr-Thr) [35]). In silico analyses [36,37] of the protein sequences of the putative PVD NRPSs: PvdI, Pflu2544, Pflu2552, Pflu2553 and PvdL, were performed to predict their amino acid substrates (results are shown in Additional file 2). Comparison of the substrate predictions with the actual PVD structure suggested that only PvdI and Pflu2544 are involved in the biosynthesis of the SBW25 PVD backbone, with predictions for three of the amino acid residues being correct (Ser, Gly and Ser). Dhb/ sal-like residues were consistently predicted for both occurrences of fOHOrn for PvdI and Pflu2544 (see Additional file 2). It is unclear why the algorithm has made this prediction, as fOHOrn does not share similar physicochemical properties with dhb and sal, however, similar analyses of the PAO1 PVD NRPSs have also consistently predicted dhb/sal-like specificities for the fOHOrn binding modules (Additional file 2). The roles of Pflu2552 and Pflu2553 are presently unknown, however the presence of an IS-box-like motif preceding these genes, and their proximity to other PVD gene homologues (Figure 1) suggests that they have, or have had, a role in PVD-mediated iron- uptake processes. As the SBW25 PVD chromophore structure is identical to that of PAO1 PVD [33], it was not surprising that the in silico substrate predictions for SBW25 PvdL were the same as those for PAO1 PvdL (Additional file 2), although only one of the three residues was predicted correctly (glu) in each case.

\section{Utilization of exogenous PVDs by P. fluorescens SBW25}

The identification of two SBW25 plant-induced genes with homology to siderophore receptor genes $[19,20]$ prompted us to examine the ability of SBW25 to uptake and utilize exogenous siderophores. Initially, a genomewide search for putative TonB-dependent siderophore receptor genes was undertaken, which revealed 24 putative siderophore receptor genes dispersed throughout the genome (listed in Additional file 3). Nine of these were immediately adjacent to predicted sigma factor/antisigma factor gene pairs (Additional file 3 ), that are presumably involved in their regulation. The number of putative receptor genes is similar to that (26) for $P$. fluorescens PfO-1 [3], and include fpvA (Pflu2545), and Pflu5798 and Pflu6132 which were both previously shown to be induced in planta [19]. These results strongly support the notion that SBW25 has the capability to utilize a considerable number of exogenous iron-chelating siderophores produced by other microbes.

To test the ability of SBW25 to utilize exogenous PVDs, PVDs purified from 25 different Pseudomonas isolates (Table 2), each with a different siderotype profile (P. Cornelis, personal communication), were supplied to 15F3 (a secondary siderophore-deficient mutant strain of PBR840) that had been overlaid as a dilute suspension onto CAA medium chelated with EDDHA. The mutant was unable to grow when water was provided as a negative control. However, growth was restored by provision of PVDs purified from 19 different isolates (Table 2). These include the three types (I, II and III) of PVD from P. aeru-

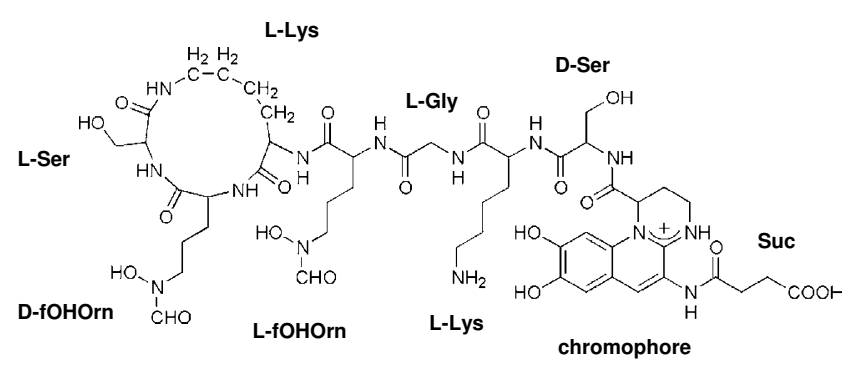

\section{Figure 5}

Chemical structure of $P$. fluorescens SBW25 PVD. Structure of SBW25 PVD with succinic acid (amide) side chain (Suc) amidically connected to the chromophore shown. The side chain may also comprise ketoglutaric acid. fOHOrn, N5-formyl-N5-hydroxyornithine. 
Table 2: Utilization of exogenous Pseudomonas PVDs

\begin{tabular}{|c|c|c|}
\hline Strain PVD isolated from & I5F3 growth stimulation & Reference \\
\hline P. aeruginosa $\mathrm{PAOI} \mathrm{a}^{\mathrm{a}}$ & + & {$[40,54]$} \\
\hline P. aeruginosa $7 \mathrm{NSK} 2^{\mathrm{a}}$ & + & [55] \\
\hline P. aeruginosa $59.20^{\mathrm{a}}$ & + & [39] \\
\hline P. agarici LMG 2112 & + & BCCM/LMGb \\
\hline P. asplenii LMG 5 I 47 & - & BCCM/LMG \\
\hline P. fluorescens LMG 14562 & + & BCCM/LMG \\
\hline P. fluorescens 17400::qbsFc & - & {$[56]$} \\
\hline P. fluorescens 5 & + & A. Sarniguet, INRA, France \\
\hline P. fluorescens C7RI2 & + & P. Lemanceau, INRA/Université de Bourgogne, France \\
\hline P. fluorescens SBW25 & + & {$[17]$} \\
\hline P. libanensis LMG 21606 & - & BCCM/LMG \\
\hline P. salomonii LMG 22120 & + & BCCM/LMG \\
\hline P. syringae LMG 1247 & + & BCCM/LMG \\
\hline P. vancouverensis LMG 20222 & - & BCCM/LMG \\
\hline Pseudomonas sp. W2Ap9 & + & S. Matthijs, VUB, Brussels \\
\hline Pseudomonas sp. W2AugI & + & S. Matthijs, VUB, Brussels \\
\hline Pseudomonas sp. W2Aug7 & + & S. Matthijs, VUB, Brussels \\
\hline Pseudomonas sp. W2Aug36 & + & S. Matthijs, VUB, Brussels \\
\hline Pseudomonas sp. W2Decl8 & + & S. Matthijs, VUB, Brussels \\
\hline Pseudomonas sp. W2Dec29 & + & S. Matthijs, VUB, Brussels \\
\hline Pseudomonas sp. W2Dec33 & - & S. Matthijs, VUB, Brussels \\
\hline Pseudomonas sp. WI5Feb3IB & + & S. Matthijs, VUB, Brussels \\
\hline Pseudomonas sp. W2Jun I4 & - & S. Matthijs, VUB, Brussels \\
\hline Pseudomonas sp. WI5Ap2 & + & S. Matthijs, VUB, Brussels \\
\hline Pseudomonas sp. WI5Aug I & + & S. Matthijs, VUB, Brussels \\
\hline Pseudomonas sp. WI5Oct32 & + & S. Matthijs, VUB, Brussels \\
\hline
\end{tabular}

a P. aeruginosa strains PAOI, 7NSK2 and 59.20 produce types I, II and III PVDs, respectively.

b BCCM/LMG: Belgian co-ordinated collections of micro-organisms bacteria collection

c Secondary siderophore (thioquinolobactin) production is inactivated in this strain.

ginosa. Thus, it is apparent that SBW25 is able to utilize a range of exogenous PVDs produced by other pseudomonads.

\section{Conclusion}

The genomic era has revolutionized the scientific method of comparative biology, where the general applicability of biological traits and systems that have often been evaluated in few model organisms may now be readily assessed across taxa. Although PVDs are common siderophores of Pseudomonas spp., the regulation of the genes involved in the biosynthesis and uptake of PVD has been elucidated almost exclusively in $P$. aeruginosa PAO1. The availability of the P. fluorescens SBW25 genome sequence has revealed that PVD genes are considerably more widespread throughout the SBW25 genome than in other sequenced pseudomonads, and has enabled a comparative analysis of PVD regulation in SBW25 and PAO1 to be undertaken. The PVD regulatory model established for PAO1 involves a unique branched signaling pathway [5]. Prior to this study it was not known whether this model applies to other Pseudomonas isolates. Using chromosomally-integrated gene reporter fusions and gene expression constructs, we found that the PAO1 branched signaling model is present in SBW25. In addition, we reveal a signif- icant difference between PAO1 and SBW25 in terms of the regulation of $f p v R$. In SBW25, over-expression of $f p v I$ results in constitutive expression of $f p v R$, suggesting that $f p v R$ is positively regulated by FpvI, rather than directly by Fur, as is the case of $f p v R$ of PAO1 [5]. The structure of SBW25 PVD was elucidated and it was found that the peptide backbone is identical to that of $P$. fluorescens ATCC 13525 , comprising a partly cyclic peptide of seven residues. The PVD structure implicated the involvement of two NRPSs in the synthesis of the PVD peptide backbone. The SBW25 genome harbors 24 putative TonB-dependent siderophore receptors, two of which are previously shown to be plant-inducible [19]. Exogenous PVD uptake assays demonstrate that SBW25 is able to utilize a variety of structurally distinct siderophores produced by other Pseudomonas isolates. These data lay the foundation for further detailed functional analysis of these putative siderophore receptors in term of regulation and transporter specificity.

\section{Methods}

Bacterial strains, plasmids, and growth conditions

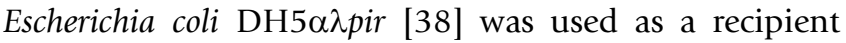
strain for gene cloning and then a donor for conjugative transfer into Pseudomonas cells. Pseudomonas strains and plasmids used in this study are listed in Table 1. E. coli cul- 
tures were grown at $37^{\circ} \mathrm{C}$ in Luria-Bertani (LB) medium [38] and P. fluorescens cultures were grown at $28^{\circ} \mathrm{C}$ in LB or casamino acids medium (CAA) [39]. Antibiotics were used at the following final concentrations $(\mu \mathrm{g} / \mathrm{ml})$ : ampicillin (Ap) 100, chloramphenicol (Cm) 25, gentamycin (Gm) 20, kanamycin (Km) 50, streptomycin (Sm) 100 and tetracycline (Tc) 10. 5-Bromo-4-chloro-3-indolyl $\beta$ D-galactopyranoside (X-gal; Melford Laboratories, Chelsworth, UK) was used at a final concentration of 40 $\mu \mathrm{g} / \mathrm{ml}$.

To monitor PVD gene activities, reporter strains were grown in the presence of $450 \mathrm{nM}-450 \mu \mathrm{M} \mathrm{FeSO}_{4}$ for iron supplemented media. To chelate iron, $100 \mu \mathrm{M} 2$, 2'-dipyridyl (Sigma, St Louis MO, USA), or $0.5 \mathrm{mg} / \mathrm{ml}$ ethylenediaminedihydroxyphenylacetic acid (EDDHA) was used. Purified PVD was supplied at $50 \mu \mathrm{M}$.

Growth curves of bacterial strains were obtained using a VersaMax microtiter plate reader with SOFTmax PRO software (Molecular Devices, Sunnyvale CA, USA). Inoculum was prepared by culturing strains stored at $-80^{\circ} \mathrm{C}$ in $\mathrm{LB}$ broth overnight, then sub-culturing into CAA broth with growth overnight. For growth experiments, cells from the CAA culture were washed once with sterile water and $2 \mu \mathrm{l}$ was used inoculate $200 \mu \mathrm{l}$ CAA or CAA supplemented with $450 \mu \mathrm{M} \mathrm{FeCl}_{3}$ in wells of the 96-well microtiter plate. Plates were incubated at $28^{\circ} \mathrm{C}$ and absorbance readings at $450 \mathrm{~nm}$ were taken every five minutes after brief shaking. Growth curves were also obtained from highly aerated cultures grown in $250 \mathrm{ml}$ flasks containing $20 \mathrm{ml}$ CAA broth, and inoculated to an initial OD450 of $\sim 0.15$. Cultures were grown at $28^{\circ} \mathrm{C}$ with shaking at $200 \mathrm{rpm}$ and absorbance readings at $450 \mathrm{~nm}$ were taken over a 24 hour period.

\section{In silico analyses}

Putative homologues of PVD-related genes in P. fluorescens SBW25 were identified by interrogating the un-annotated SBW25 genome [22] with P. aeruginosa PAO1 PVD gene sequences $[23,40]$ using nucleotide-nucleotide Basic Local Alignment Search Tool (BLASTN). Complete SBW25 open reading frames (ORFs) were identified from matching sequence hits, and these were used to re-query the PAO1 genome via translated query vs. protein sequence BLAST (tBLASTX) algorithms. Sequences upstream of putative homologues were examined by eye for the PAO1 Fur-box consensus sequence, 5'-GATAATGATAATCATTATC-3' [11], and iron starvation (IS) boxes, 5'-TAAAT-N ${ }_{16}$-CGT-3' $[12,41]$. The best matches to Furbox motifs were confirmed using MotifScanner [42], in conjunction with a Fur-box position weight matrix (accession MX000013) from the Prodoric website [43,44]. Genes were mapped to the genome using Artemis software [45], and the percentage identity and similarity at the amino acid sequence level between PAO1 and SBW25 homologues was determined by the Needleman-Wunsch global alignment algorithm implemented in EMBOSS needle [46]. Common DNA sequence motifs were identified by MEME version 3.0 [37]. In silico PVD peptide backbone structural predictions were conducted using the methods of Rausch et al. and Stachelhaus et al.[36,37] implemented in NRPSpredictor [47]. Putative siderophore receptor genes were identified by hits to protein family (Pfam) accessions PF00593 (TonB-dependent receptor) and PF07715 (TonB-dependent receptor plug domain) [22], in combination with BLAST homology to putative siderophore receptor genes. Putative sigma factor and anti-sigma factor genes adjacent to receptor genes were identified by hits to Pfam accessions PF04542 (Sigma-70 region) and PF04773 (FecR protein), respectively.

\section{Gene reporter and expression constructs}

DNA manipulation was performed by standard techniques [38]. Promoter reporter fusion strains were generated by cloning the promoter region in the front of a promoterless 'lacZ carried in the cloning vector PIVET-Sm, a $\mathrm{Sm}^{\mathrm{R}}$ derivative of pIVETD [19]. Promoter regions were created by PCR amplifying regions upstream of, and including the 5'-portion of PVD genes using primers listed in Table 3. To facilitate directional cloning, BglII and XhoI sites were incorporated into the 5 '-ends of the sense and anti-sense strand primers, respectively. PCR products were digested with BglII and XhoI, and ligated to BglII-XhoI digested pIVETD-Sm, creating fusions to promoterless 'lacZ. Reporter strains were created by transforming SBW25 with the promoter fusion constructs via electroporation or conjugation. Transformants were selected based on streptomycin resistance and PCR screened using a primer upstream of the cloned promoter fragment and a 'lacZ primer to confirm the construct had integrated into the genome by single-crossover homologous recombination within the cloned PVD promoter fragment region.

Gene expression constructs for $p v d S, f p v I$ and $f p v R$ were created using the Gateway cloning system (Invitrogen). Fragments containing the ribosome-binding site and entire ORF of $p v d S, f p v I$ and $f p v R$ were PCR-amplified using primers in Table 3. Fragments were directionally cloned into pENTR/D-TOPO (Invitrogen) following the manufacturers instructions. The sequences of the cloned fragments were verified, and LR recombination reactions using Gateway LR Clonase enzyme mix (Invitrogen) were performed to transfer the cloned fragment to the broad host range destination expression vector, pBroadgate (gift from R. Thwaites and J. Mansfield). pBroadgate is a derivative of pBBR1MCS-5 [48] that has been modified as a Gateway destination vector by incorporation of an attR cassette, containing a $\mathrm{Cm}$ resistance determinant and a 
Table 3: Oligonucleotide primers used in this study.

\begin{tabular}{|c|c|c|}
\hline Primer & Sequence $\left(5^{\prime}-3^{\prime}\right)^{a}$ & Application \\
\hline CM-030 & GGGAGATCTAGGTCCACATTGGATTGCAGG & pvdS promoter \\
\hline CM-038 & CCGCTCGAGGGTGAAGCGCCGTGAATAACCACA & prdS promoter \\
\hline CM-036 & GGAAGATCTCCTGTGGATACTTGTTCCGTCA & pvdL promoter \\
\hline CM-037 & CCGCTCGAGACCAAAGAACGCCGCGACGTAATC & pvdL promoter \\
\hline CM-050 & GGAAGATCTCTGCTGGGCGTTGAGGGTCTGG & fpvl promoter \\
\hline CM-05I & CCGCTCGAGCGGGAAATGCACAGGCGTTCGGCA & fpvl promoter \\
\hline CM-052 & GGAAGATCTCGTCTGCAGCGTCTGGTCCTGGAG & fpvR promoter \\
\hline CM-053 & CCGCTCGAGGTCCTTGTAGTTGCTGTAGACCAG & $f p v R$ promoter \\
\hline CM-II6 & GGGAGATCTGAAGTAGGAACGTGTCACTAGTGG & fpvA promoter \\
\hline CM-II7 & GGGCTCGAGGTCGAAGTGCCTGCCAGCAAG & fpvA promoter \\
\hline CM-IIO & CACCGTGTAGGAGGCCTCAGCAAGG & prdS ORF \\
\hline CM-III & ACATAAGGCGCACATTTCATCTGC & pvdS ORF \\
\hline CM-II2 & CACCACTCAGGGACCTAATGCCGC & fpvl ORF \\
\hline CM-II3 & CATGTGTTGATAGGAAACGAGGAC & fpvl ORF \\
\hline CM-II4 & CACCCGTGAAGTTAGAATGTGGG & fpvR ORF \\
\hline CM-II5 & TGGGCGGTTCAGGGCATG & $f p v R$ ORF \\
\hline pvdLI & GAAGATCTTCGAACTTCCCCAAACGCT & pvdL deletion \\
\hline pvdL2 & CAGCATGCGGATCCGTTGACGGAACCCGCAGCGCGGGGATGCC & pvdL deletion \\
\hline pvdL3 & TCCGTCAACGGATCCGCATGCTGTGGCGCACCAATGGCTGCT & prdL deletion \\
\hline pvdL4 & GAAGATCTCCAACTCCGCCATCAAATCA & prdL deletion \\
\hline
\end{tabular}

a Underlined sequences denote Bglll or Xhol restriction sites to facilitate cloning; sequences in bold type are tag for directional topoisomerasemediated cloning, and sequences in italics denote random complementary sequences to facilitate SOE-PCR [50].

lethal $c c d$ B gene (Invitrogen). P. fluorescens reporter strains were transformed with expression and pBroadgate-D control constructs by electroporation.

\section{$\beta$-galactosidase assays}

$\beta$-galactosidase activities of 'lacZ reporter fusion strains were determined from cultures grown to mid- to late log phase in CAA media, supplemented with $\mathrm{FeSO}_{4}$ or 2,2'dipyridyl as required. Assays were based on the hydrolysis of 4-methylumbelliferyl- $\beta$-D-galactoside to yield the fluorescent product, 7-hydroxy-4-methylcoumarin (4MU) as described [49]. 4MU was detected at $460 \mathrm{~nm}$ after excitation at $365 \mathrm{~nm}$ using a Hoefer DyNA Quant 200 fluorometer (Pharmacia Biotech, San Francisco CA, USA), or FLUOstar (BMG Labtech, Offenburg, Germany).

\section{Construction of PBR840 ( $\triangle \mathrm{pvdL}$ )}

An ORF Pflu4387 ( $p v d L$ ) knockout mutant was constructed by deleting a $10.9 \mathrm{~kb}$ internal portion of the 12.9 $\mathrm{kb} p v d L$ gene. This was achieved by a combination of gene splicing by overlap extension (SOE) PCR [50] and a twostep allelic exchange strategy [20]. Briefly, two $1 \mathrm{~kb}$ fragments from each of the 5'- and 3'-end of pvdL were PCRamplified from SBW25 genomic DNA using the primer pairs pvdL1 and pvdL2, and pvdL3 and pvdL4, respectively (Table 3 ). The two fragments were ligated in a third PCR using primers pvdL1 and pvdL4 via the complementary residues incorporated at the 5 '-ends of primers pvdL2 and pvdL3 (Table 3 ). The resulting $2 \mathrm{~kb}$ pvdL deletion fragment was cloned into pCR8/GW/TOPO (Invitrogen). After the sequence of the cloned fragment was verified, the fragment was retrieved by BglII digestion and cloned into the integration vector pUIC3 to create pUIC3-40.

To generate a chromosomal pvdL deletion, pUIC3-40 was mobilized into $P$. fluorescens SBW25 by conjugation with the help of pRK2013 (tra+). Chromosomal integration of pUIC3-40 by a single homologous recombination event was selected by plating transconjugants on LB agar containing Tc and X-gal. Blue, Tc-resistant colonies contained both intact and deleted versions of $p v d L$, and were grown in LB broth without selection to allow the second homologous recombination event to take place. After two consecutive overnight subcultures, cells were plated on LB agar containing X-gal. White colonies were screened for Tc sensitivity, and the pvdL deletion was confirmed by PCR analysis.

\section{PVD structure determination}

To determine the structure of SBW25 PVD, mass spectral data were obtained with a MAT 900 ST instrument providing an EB-QIT (quadrupole ion trap) geometry and equipped with an ESI II ion source (Finnigan MAT, Bremen, Germany); spray voltage 3.4-3.6 kV, capillary temperature $230^{\circ} \mathrm{C}$. Source conditions were set to minimize fragmentation, resolution ca. 5000 (10\% valley). Trifluoroacetic acid was added to the sample dissolved in water (100:0.2, v/v). Fragmentation induced by low energy collision activation was effected in the octapole unit, located in front of the QIT and in the QIT itself $(\sim 2 \cdot 10-3 \mathrm{~Pa}$ He as bath gas diffusing in the collision octapole). 


\section{PVD purification and exogenous siderophore uptake by SBW25}

PVD was purified from bacterial cultures grown for $48 \mathrm{~h}$ in $1 \mathrm{l}$ of CAA at $28^{\circ} \mathrm{C}$. For $P$. aeruginosa, the strains were grown at $37^{\circ} \mathrm{C}$. The cell-free supernatant was passed on a C-18 column $(5 \times 2.5 \mathrm{~cm})$ conditioned with methanol and rinsed with sterile $\mathrm{H}_{2} \mathrm{O}$. PVD was eluted with $80 \%$ methanol. Subsequently the methanol was evaporated and the PVD lyophilized. Purified PVD was quantified spectrophotometrically [39].

To estimate the diversity of exogenous PVDs that may be utilized by SBW25, PVDs were purified from a panel of 25 Pseudomonas isolates and strains, representing a high diversity of species that had previously been shown to each produce a unique PVD (each having a unique siderotype) as shown by isoelectric focusing (S. Matthijs, unpublished). These isolates included Pseudomonas type strains, and environmental isolates collected from the Woluwe river, Brussels, Belgium (Table 2). CAA agar plates containing $0.5 \mathrm{mg} / \mathrm{ml}$ EDDHA were overlaid with 5 $\times 10^{6}$ cells of strain $15 \mathrm{~F} 3$, a siderophore-deficient derivative of PBR840 that contains transposon mini-Tn phoA3 disruption of biosynthetic genes for a secondary siderophore (S. Matthijs, unpublished). Filter-paper disks impregnated with $5 \mu \mathrm{l}$ of $8 \mathrm{mM}$ purified siderophore were placed on the agar [39]. Plates were incubated at $28^{\circ} \mathrm{C}$ and scored for the presence of detectable growth after one day.

\section{List of abbreviations used}

CAA, casamino acids medium; EDDHA, ethylenediaminedihydroxyphenylacetic acid; IVET, in vivo expression technology; LB, Luria-Bertani; NRPS, non-ribosomal peptide synthetase; PCR, polymerase chain reaction; PVD, pyoverdine; QIT, quadrupole ion trap; SOE, splicing by overlap extension; X-gal, 5-bromo-4-chloro-3-indolyl $\beta$ D-galactopyranoside; 4MU， 7-hydroxy-4-methylcoumarin.

\section{Authors' contributions}

CDM conducted the bioinformatic and genetic work, and drafted the manuscript. XXZ created the $\Delta p v d L$ mutant, assessed growth characteristics, and contributed to the manuscript. SM performed the assay for the heterologous usage of PVDs. MS and HB determined the structure of SBW25 PVD. PBR assisted with experimental design and critically reviewed the manuscript. All authors have read and approved the final manuscript.

\section{Additional material}

\section{Additional file 1}

List of P. fluorescens SBW25 genes with predicted function in PVD biosynthesis and uptake in comparison with homologues in $\mathrm{P}$. aeruginosa PAO1. The data list all putative PVD genes identified in SBW25, and show predicted amino acid identities to their PAO1 homologues.

Click here for file

[http://www.biomedcentral.com/content/supplementary/14712180-8-7-S1.doc]

\section{Additional file 2}

NRPS substrate in silico predictions. The data show the substrates of the PVD NRPS modules predicted by specificity conferring code and transductive support vector machine methods.

Click here for file

[http://www.biomedcentral.com/content/supplementary/14712180-8-7-S2.doc]

\section{Additional file 3}

List of putative siderophore receptors in $P$. fluorescens SBW25. The data list all putative siderophore receptors in the SBW25 genome, and whether these are adjacent to predicted sigma factor/anti-sigma factor gene pairs. Click here for file

[http://www.biomedcentral.com/content/supplementary/14712180-8-7-S3.doc]

\section{Acknowledgements}

We are grateful to I.L. Lamont and P. Cornelis for helpful discussions. Many thanks also to R.W. Jackson for statistical analyses and helpful discussion, Z.A. Park-Ng for statistical analyses, S.R. Giddens and C.G. Knight for bioinformatics support, R. Thwaites and J. Mansfield for the kind gift of pBroadgate, and J. Bull for technical support. This research was supported by a grant from the Biotechnology and Biological Sciences Research Council, U.K. to P.B.R.

\section{References}

I. Neilands JB: Siderophores: structure and function of microbial iron transport compounds. J Biol Chem 1995, 270(45):26723-26726.

2. Crosa JH: Signal transduction and transcriptional and posttranscriptional control of iron-regulated genes in bacteria. Microbiol Mol Biol Rev 1997, 6 I (3):319-336.

3. Cornelis P, Matthijs S: Diversity of siderophore-mediated iron uptake systems in fluorescent pseudomonads: not only pyoverdines. Environ Microbiol 2002, 4(I 2):787-798.

4. Meyer JM: Pyoverdines: pigments, siderophores and potential taxonomic markers of fluorescent Pseudomonas species. Arch Microbiol 2000, 174(3): I35- I 42

5. Beare PA, For RJ, Martin LW, Lamont IL: Siderophore-mediated cell signalling in Pseudomonas aeruginosa: divergent pathways regulate virulence factor production and siderophore receptor synthesis. Mol Microbiol 2003, 47(I):195-207.

6. Vasil ML, Ochsner UA: The response of Pseudomonas aeruginosa to iron: genetics, biochemistry and virulence. Mol Microbiol 1999, 34(3):399-4I3.

7. Lamont IL, Beare PA, Ochsner U, Vasil AI, Vasil ML: Siderophoremediated signaling regulates virulence factor production in Pseudomonas aeruginosa. Proc Natl Acad Sci USA 2002, 99( I0):7072-7077. 
8. Redly GA, Poole K: FpvIR control of fpvA ferric pyoverdine receptor gene expression in Pseudomonas aeruginosa: demonstration of an interaction between Fpvl and FpvR and identification of mutations in each compromising this interaction. J Bacteriol 2005, I 87( I 6):5648-5657.

9. Lamont IL, Martin LW, Sims T, Scott A, Wallace M: Characterization of a gene encoding an acetylase required for pyoverdine synthesis in Pseudomonas aeruginosa. J Bacteriol 2006, | 88(8):3|49-3| 52.

10. Prince RW, Cox CD, Vasil ML: Coordinate regulation of siderophore and exotoxin A production: molecular cloning and sequencing of the Pseudomonas aeruginosa fur gene. Bacteriol 1993, I 75(9):2589-2598.

II. Ochsner UA, Vasil ML: Gene repression by the ferric uptake regulator in Pseudomonas aeruginosa: cycle selection of iron-regulated genes. Proc Natl Acad Sci USA 1996, 93(9):4409-44I4.

12. Wilson MJ, McMorran BJ, Lamont IL: Analysis of promoters recognized by PvdS, an extracytoplasmic-function sigma factor protein from Pseudomonas aeruginosa. J Bacteriol 200I, | 83(6):2| $15|-2| 55$.

13. Cunliffe HE, Merriman TR, Lamont IL: Cloning and characterization of pvdS, a gene required for pyoverdine synthesis in Pseudomonas aeruginosa: PvdS is probably an alternative sigma factor. J Bacteriol I995, I 77( ( 0):2744-2750.

14. Redly GA, Poole K: Pyoverdine-mediated regulation of FpvA synthesis in Pseudomonas aeruginosa: involvement of a probable extracytoplasmic-function sigma factor, Fpvl. J Bacteriol 2003, I85(4): | 26|-|265.

15. Loper JE, Henkels MD: Utilization of heterologous siderophores enhances levels of iron available to Pseudomonas putida in the rhizosphere. Appl Environ Microbiol 1999, 65(I2):5357-5363.

16. Molina MA, Godoy P, Ramos-Gonzalez MI, Munoz N, Ramos JL, Espinosa-Urgel M: Role of iron and the TonB system in colonization of corn seeds and roots by Pseudomonas putida KT2440. Environ Microbiol 2005, 7(3):443-449.

17. Bailey MJ, Lilley AK, Thompson IP, Rainey PB, Ellis RJ: Site directed chromosomal marking of a fluorescent pseudomonad isolated from the phytosphere of sugar beet; stability and potential for marker gene transfer. Mol Ecol 1995, 4(6):755-763.

18. Ellis RJ, Timms-Wilson TM, Bailey MJ: Identification of conserved traits in fluorescent pseudomonads with antifungal activity. Environ Microbiol 2000, 2(3):274-284.

19. Gal M, Preston GM, Massey RC, Spiers AJ, Rainey PB: Genes encoding a cellulosic polymer contribute toward the ecological success of Pseudomonas fluorescens SBW25 on plant surfaces. Mol Ecol 2003, I 2(I I):3109-3 I 2 I.

20. Rainey PB: Adaptation of Pseudomonas fluorescens to the plant rhizosphere. Environ Microbiol I999, I (3):243-257.

21. Mossialos D, Ochsner U, Baysse C, Chablain P, Pirnay JP, Koedam N, Budzikiewicz H, Fernández DU, Schäfer M, Ravel J, Cornelis P: Identification of new, conserved, non-ribosomal peptide synthetases from fluorescent pseudomonads involved in the biosynthesis of the siderophore pyoverdine. Mol Microbiol 2002, 45(6): 1673-1685.

22. http://www.sanger.ac.uk/Projects/P_fluorescens/ [http:// www.sanger.ac.uk/Projects/P fluorescens/]

23. Ravel J, Cornelis P: Genomics of pyoverdine-mediated iron uptake in pseudomonads. Trends Microbiol 2003, II(5): 195-200.

24. Smith EE, Sims EH, Spencer DH, Kaul R, Olson MV: Evidence for diversifying selection at the pyoverdine locus of Pseudomonas aeruginosa. / Bacteriol 2005, I87(6):2 I38-2 I 47

25. Paulsen IT, Press CM, Ravel J, Kobayashi DY, Myers GSA, Mavrodi DV, DeBoy RT, Seshadri R, Ren Q, Madupu R, Dodson RJ, Durkin AS, Brinkac LM, Daugherty SC, Sullivan SA, Rosovitz MJ, Gwinn ML, Zhou L, Schneider DJ, Cartinhour SW, Nelson WC, Weidman J, Watkins K, Tran K, Khouri H, Pierson EA, Pierson LS, Thomashow LS, Loper JE: Complete genome sequence of the plant commensal Pseudomonas fluorescens Pf-5. Nature Biotechnol 2005, 23(7):873-878.

26. Koster M, van Klompenburg W, Bitter W, Leong J, Weisbeek P: Role for the outer membrane ferric siderophore receptor PupB in signal transduction across the bacterial cell envelope. EMBO J I994, I3(1 2):2805-28I3.
27. Visca P, Leoni L, Wilson MJ, Lamont IL: Iron transport and regulation, cell signalling and genomics: lessons from Escherichia coli and Pseudomonas. Mol Microbiol 2002, 45(5): I I77-I 190.

28. Fuchs R, Budzikiewicz $\mathrm{H}$ : Structural studies of pyoverdins by mass spectroscopy. Curr Org Chem 200I, 5:265-288.

29. Budzikiewicz H, Schäfer M, Fernández DU, Matthijs S, Cornelis $P$ : Characterization of the chromophores of pyoverdins and related siderophores by electrospray tandem mass spectrometry. BioMetals 2007, 20(2): | 35- | 44

30. Budzikiewicz H, Schäfer M, Meyer JM: Siderotyping of fluorescent pseudomonads - problems in the determination of molecular masses by mass spectrometry. Mini- Rev Org Chem 2007, 4:246-253.

3I. Fuchs R, Budzikiewicz H: Structural studies of pyoverdins with cyclopeptidic substructures by electrospray ionization and collision induced fragmentation. Spectroscopy 2000, 14:229-246.

32. Hohlneicher U, Hartmann R, Taraz K, Budzikiewicz H: Pyoverdin, ferribactin, azotobactin - a new triade of siderophores from Pseudomonas chlororaphis ATCC 9446 and its relation to Pseudomonas fluorescens ATCC 13525. Z Naturforsch 1995, 50:337-344.

33. Budzikiewicz H: Siderophores of the Pseudomonadaceae sensu stricto (fluorescent and non-fluorescent Pseudomonas spp.). Prog Ch Org Nat Prod 2004, 87:8I-237.

34. Linget C, Azadi P, MacLeod JK, Dell A, Abdallah MA: Bacterial siderophores: The structures of the pyoverdins of Pseudomonas fluorescens ATCC 13525. Tetrahedron Lett 1992, 33(13): I737- 1740 .

35. Abdallah MA: Pyoverdines and pseudobactins. In CRC handbook of microbial iron chelates Edited by: Winkelmann G. Boca Raton, Florida CRC Press.: 1991:139-152.

36. Rausch C, Weber T, Kohlbacher O, Wohlleben W, Huson DH: Specificity prediction of adenylation domains in nonribosomal peptide synthetases (NRPS) using transductive support vector machines (TSVMs). Nucleic Acids Res 2005, 33(18):5799-5808.

37. Stachelhaus T, Mootz HD, Marahiel MA: The specificity-conferring code of adenylation domains in nonribosomal peptide synthetases. Chem Biol 1999, 6(8):493-505.

38. Sambrook J, Fritsch EF, Maniatis T: Molecular Cloning: A Laboratory Manual. 2nd edition. Plainview , Cold Spring Harbor Laboratory Press; 1989.

39. Meyer JM, Stintzi A, De Vos D, Cornelis P, Tappe R, Taraz K, Budzikiewicz $H$ : Use of siderophores to type pseudomonads: the three Pseudomonas aeruginosa pyoverdine systems. Microbiology 1997, 143:35-43.

40. Stover CK, Pham XQ, Erwin AL, Mizoguchi SD, Warrener P, Hickey MJ, Brinkman FS, Hufnagle WO, Kowalik DJ, Lagrou M, Garber RL, Goltry L, Tolentino E, Westbrock-Wadman S, Yuan Y, Brody LL, Coulter SN, Folger KR, Kas A, Larbig K, Lim R, Smith K, Spencer D, Wong GK, Wu Z, Paulsen IT, Reizer J, Saier MH, Hancock RE, Lory S, Olson MV: Complete genome sequence of Pseudomonas aeruginosa PAOI, an opportunistic pathogen. Nature 2000, 406(6799):959-964.

4I. Lamont IL, Martin LW: Identification and characterization of novel pyoverdine synthesis genes in Pseudomonas aeruginosa. Microbiology 2003, 149:833-842.

42. Thijs G, Lescot M, Marchal K, Rombauts S, De Moor B, Rouzé P, Moreau $Y$ : A higher order background model improves the detection of regulatory elements by Gibbs Sampling. Bioinformatics 200I, I7(12):I II3-II22.

43. http://prodoric.tu-bs.de [http://prodoric.tu-bs.de]

44. Münch R, Hiller K, Barg H, Heldt D, Linz S, Wingender E, Jahn D: PRODORIC: prokaryotic database of gene regulation. Nucleic Acids Res 2003, 3 I ( I):266-269.

45. Rutherford K, Parkhill J, Crook J, Horsnell T, Rice P, Rajandream MA, Barrell B: Artemis: sequence visualisation and annotation. Bioinformatics 2000, 16( I 0):944-945

46. Rice P, Longden I, Bleasby A: EMBOSS: The European Molecular Biology Open Software Suite. Trends Genet 2000, 16(6):276-277

47. http://www-ab.informatik.uni-tuebingen.do/software [http:// www-ab.informatik.uni-tuebingen.de/toolbox/ index.php?view=domainpred]

48. Kovach ME, Elzer PH, Hill DS, Robertson GT, Farris MA, Roop RM 2nd, Peterson KM: Four new derivatives of the broad-host- 
range cloning vector pBBRIMCS, carrying different antibiotic-resistance cassettes. Gene 1995, 166(1):175-176.

49. Pharmacia B: Hoefer DyNA Quant 200 Fluorometer User Manual.

50. Horton RM, Hunt HD, Ho SN, Pullen JK, Pease LR: Engineering hybrid genes without the use of restriction enzymes: gene splicing by overlap extension. Gene 1989, 77:6I-68.

51. Prentki P, Krisch HM: In vitro insertional mutagenesis with a selectable DNA fragment. Gene 1984, 29(3):303-313.

52. Figurski DH, Helinski DR: Replication of an origin-containing derivative of plasmid RK2 dependent on a plasmid function provided in trans. Proc Natl Acad Sci USA 1979, 76(4): I648-1652.

53. Giddens SR, Jackson RW, Moon CD, Jacobs MA, Zhang XX, Gehrig SM, Rainey PB: Mutational activation of niche-specific genes provides insight into regulatory networks and bacterial function in a complex environment. Proc Natl Acad Sci USA 2007, 104(46): 18247-| 8252.

54. Holloway BW: Genetic recombination in Pseudomonas aeruginosa. J Gen Microbiol 1955, I3(3):572-58I.

55. Höfte $M$, Mergeay $M$, Verstraete $W$ : Marking the rhizopseudomonas strain 7NSK2 with a Mu d(lac) element for ecological studies. Appl Environ Microbiol I990, 56(4): 1046-1052.

56. Matthiis S, Baysse C, Koedam N, Tehrani KA, Verheyden L, Budzikiewicz $\mathrm{H}$, Schafer M, Hoorelbeke B, Meyer JM, De Greve H, Cornelis $P$ : The Pseudomonas siderophore quinolobactin is synthesized from xanthurenic acid, an intermediate of the kynurenine pathway. Mol Microbiol 2004, 52(2):37I-384.

Publish with Bio Med Central and every scientist can read your work free of charge

"BioMed Central will be the most significant development for disseminating the results of biomedical research in our lifetime. "

Sir Paul Nurse, Cancer Research UK

Your research papers will be:

- available free of charge to the entire biomedical community

- peer reviewed and published immediately upon acceptance

- cited in PubMed and archived on PubMed Central

- yours - you keep the copyright

Submit your manuscript here:

http://www.biomedcentral.com/info/publishing_adv.asp
BiolMedcentral 